\title{
Roles of specific aminoglycoside-ribosome interactions in the inhibition of translation
}

\author{
LANQING YING, HONGKUN ZHU, SHINICHIRO SHOJI, and KURT FREDRICK \\ Department of Microbiology and Center for RNA Biology, The Ohio State University, Columbus, Ohio 43210, USA
}

\begin{abstract}
Aminoglycosides containing a 2-deoxystreptamine core (AGs) represent a large family of antibiotics that target the ribosome. These compounds promote miscoding, inhibit translocation, and inhibit ribosome recycling. AG binding to helix $\mathrm{h} 44$ of the small subunit induces rearrangement of A-site nucleotides A1492 and A1493, which promotes a key open-to-closed conformational change of the subunit and thereby increases miscoding. Mechanisms by which AGs inhibit translocation and recycling remain less clear. Structural studies have revealed a secondary AG binding site in H69 of the large subunit, and it has been proposed that interaction at this site is crucial for inhibition of translocation and recycling. Here, we analyze ribosomes with mutations targeting either or both AG binding sites. Assaying translocation, we find that ablation of the h44 site increases the $\mathrm{IC}_{50}$ values for AGs dramatically, while removal of the $\mathrm{H} 69$ site increases these values modestly. This suggests that the AG-h44 interaction is primarily responsible for inhibition, with H69 playing a minor role. Assaying recycling, we find that mutation of h44 has no effect on AG inhibition, consistent with a primary role for AGH69 interaction. Collectively, these findings help clarify the roles of the two AG binding sites in mechanisms of inhibition by these compounds.
\end{abstract}

Keywords: protein synthesis; ribosome; translocation; tRNA; mRNA

\section{INTRODUCTION}

Aminoglycosides are chemically diverse antibiotics widely used to treat bacterial infections (Magnet and Blanchard 2005). Most aminoglycosides are structurally similar and contain a central 2-deoxystreptamine (2-DOS) ring. These aminoglycosides (henceforth abbreviated "AGs") fall into two subgroups: 4,5-substituted 2-DOS compounds, exemplified by neomycin (Neo) and paromomycin (Par); and 4,6-substituted 2-DOS compounds, exemplified by gentamicin (Gen) and tobramycin (Tob). These AGs bind to ribosomal RNA (rRNA) and exert multiple effects on bacterial protein synthesis. They cause mRNA miscoding (Davies et al. 1965, 1966), inhibit mRNA-tRNA translocation (Cabañas et al. 1978; Misumi et al. 1978), and inhibit ribosome recycling (Hirokawa et al. 2002).

The primary binding site of AGs lies in helix 44 (h44) of the $16 \mathrm{~S}$ rRNA, near the A site of the $30 \mathrm{~S}$ subunit. Previous studies have shown that single mutations in h44 (e.g., A1408G, G1491U, or U1495A) are sufficient to confer high-level resistance to various $A G s$ in vivo (Recht and Puglisi 2001; Hobbie et al. 2005, 2006a,b; Nessar et al. 2011; Salian et al. 2012; Perez-Fernandez et al. 2014).

Corresponding author: fredrick.5@osu.edu

Article is online at http://www.rnajournal.org/cgi/doi/10.1261/rna. 068460.118.
These mutations disrupt key interactions between helix h44 and functional groups of ring I and/or II, thereby reducing $A G$ affinity.

AGs stabilize tRNA in the A site, and structural studies provide an explanation for this activity (Carter et al. 2000; Ogle et al. 2001, 2002, 2003; Peske et al. 2004; Walker and Fredrick 2006). Co-crystal structures have shown that Neo, Par, and Gen bind h44 in a similar way (Fig. 1; Carter et al. 2000; Ogle et al. 2001; Borovinskaya et al. 2007a). Ring I intercalates into h44, stacking on G1491 and forming hydrogen bonds with A1408. This occludes A1492 and A1493 from within h44, inducing a "flipped out" conformation of these nucleotides. Similar conformational changes of A1492 and A1493 normally occur upon codonanticodon pairing in the A site. Thus, AG binding to h44 reduces the energy barrier of this rearrangement, which promotes A-site tRNA (A-tRNA) binding and decoding errors (Ogle et al. 2003; Satpati et al. 2014; Zhang et al. 2018). By stabilizing A-tRNA, this rearrangement also inhibits translocation, because A-tRNA cannot readily move to the P site (Peske et al. 2004; Shoji et al. 2006).

(C) 2019 Ying et al. This article is distributed exclusively by the RNA Society for the first 12 months after the full-issue publication date (see http://rnajournal.cshlp.org/site/misc/terms.xhtml). After 12 months, it is available under a Creative Commons License (Attribution-NonCommercial 4.0 International), as described at http:// creativecommons.org/licenses/by-nc/4.0/. 
A

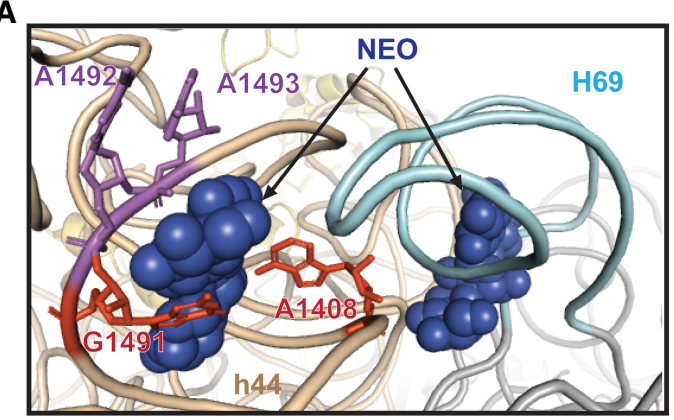

B

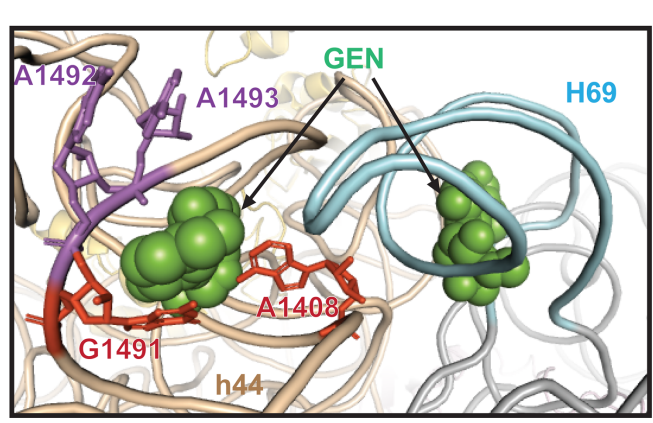

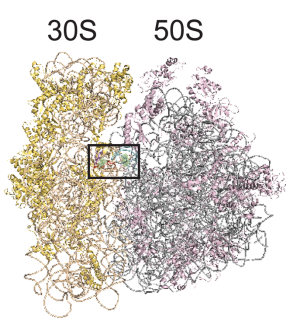

FIGURE 1. 2-DOS aminoglycosides bind h44 and H69 of the ribosome in a similar way. Cocrystal structures with $\mathrm{Neo}(A)$ and $\mathrm{Gen}(B)$ are shown as examples. Thumbnail on the right shows the perspective of view. 16S rRNA is colored beige, with key A-site nt A1492 and A1492 (violet) and h44 nt A1408 and G1491 (red) highlighted. 23S rRNA is colored gray, with $\mathrm{H} 69$ highlighted in light cyan. Aminoglycosides (as indicated) are shown as space-filled models. Images were made using PDB entries 4V52 and 4V53.

The X-ray crystallography studies revealed that AGs bind not only h44 but also helix H69 of the 50S subunit (Fig. 1; Borovinskaya et al. 2007a). H69 contacts a number of $16 \mathrm{~S}$ rRNA nucleotides, including nt 1406-1409 and 1494-1495 of h44, forming intersubunit bridge B2a/d (Liu and Fredrick 2016). This bridge plays an important role in translation initiation (Liu and Fredrick 2015) and needs to be disrupted during the subunit-splitting step of ribosome recycling. Co-crystal structures showed that ribosome recycling factor (RRF) displaces $\mathrm{H} 69$ from its normal position, disrupting B2a/d (Borovinskaya et al. 2007a). Binding of AG to the major groove of H69 reverses these effects of RRF, presumably by stabilizing bridge B2a/ $d$. This may explain the mechanism by which AGs inhibit ribosome recycling (Borovinskaya et al. 2007a).

It has been suggested that AG-H69 interaction also plays a key role in the inhibition of translocation. In single-molecule studies, Blanchard and coworkers found that an EF-G-dependent conformational change was inhibited by Neo, and mutation A1408G of h44 had no bearing on the observed inhibition (Wang et al. 2012). At the time, they attributed to this conformational change to translocation and proposed that, by binding H69, Neo stabilizes a partially rotated conformation of the ribosome and thereby blocks translocation. However, this model is difficult to reconcile with the fact that the mutation A1408G confers highlevel resistance to $\mathrm{Neo}$ in cell growth assays (MIC $>800 \mu \mathrm{M}$ ) (Recht and Puglisi 2001; Hobbie et al. 2006b).

To clarify the contribution of the two AG binding sites, we examined reassociated mutant ribosomes with either or both sites ablated. We find that the inhibition of translocation is primarily due to AG-h44 interaction, whereas the inhibition of ribosome recycling is independent of the h44 site.

\section{RESULTS}

\section{Inhibition of translocation by aminoglycosides depends largely on the h44 site}

To determine the contribution of h44 and $\mathrm{H} 69$ binding sites to $A G$ activities, we targeted each by mutagenesis. To abrogate the h44 site, we introduced A1408G or dual A1408G/G1491U substitutions. Mutation A1408G and G1491U each confers a distinct spectrum of AG resistance (Hobbie et al. 2006a). Cells carrying both mutations grew normally and were highly resistant to multiple AGs in vivo, consistent with earlier studies (Hobbie et al. 2006b). To eliminate the H69 site, we used mutation $\triangle \mathrm{H} 69$, which replaces the entire helix with a single nucleotide (Ali et al. 2006; Liu and Fredrick 2015). $30 S$ subunits were purified from an $E$. coli $\Delta 7$ prrn strain, using conventional sucrose-gradient sedimentation (Qin et al. 2007), while aptamer-tagged 50S subunits were purified using affinity chromatography, as previously described (Youngman and Green 2005). 70 S ribosomes were then formed by reassociation of control and/or mutant subunits, yielding ribosomes with no, one, or both AG binding sites mutated. Previous work has shown that rates of translocation in tagged and reassociated control ribosomes and in wild-type tight-couple ribosomes are comparable (Walker et al. 2008; Devaraj et al. 2009; Liu and Fredrick 2013).

It is well known that AGs can completely inhibit translocation (Cabañas et al. 1978; Fredrick and Noller 2003; Studer et al. 2003; Shoji et al. 2006). Accordingly, we measured the effects of various $A G s$ on the extent of translocation by toeprinting, which tracks mRNA position in the ribosome (Hartz et al. 1989; Fredrick and Noller 2002; McGarry et al. 2005; Shoji et al. 2006). Complexes containing message m291 (Shoji et al. 2006), tRNA ${ }^{\text {fMet }}$ in the P site, and $\mathrm{N}$-acetyl-Phe-tRNA ${ }^{\text {Phe }}$ in the $A$ site were made and 
incubated with various concentrations of AG. EF-G and GTP were then added, and the extent of translocation was determined (Fig. 2). In the absence of $A G$, the fraction of post-translocation (POST) state ribosomes observed was $\sim 0.5$, somewhat lower than the value expected $(\sim 0.8)$ from earlier studies involving tight-couple ribosomes (Fredrick and Noller 2003; Shoji et al. 2006; Balakrishnan et al. 2014). This could be due to partial A-site occupancy, a portion of $30 \mathrm{~S}$ complexes, and/or a portion of inactive $50 \mathrm{~S}$ subunits. The extent of translocation decreased as a function of AG concentration. Neo strongly inhibited translocation in control ribosomes, with an $\mathrm{IC}_{50}$ value of $0.4 \mu \mathrm{M}$ (Table 1; Fig. 2C). The dual A1408G/G1491U mutation of h44 increased the $\mathrm{IC}_{50}$ by 100 -fold. The activity of Par, another 4,5-substituted 2-DOS aminoglycoside, was also substantially weakened by mutation A1408G/G1491U (Table 1; Fig. 2D). The 4,6-substituted 2-DOS AGs Gen and Tob were also investigated. Mutation A1408G/G1491U completely relieved the inhibition by Gen (Fig. 2E) and increased the $\mathrm{IC}_{50}$ of Tob by $>30$-fold (Table $1 ;$ Fig. 2F). We also compared the effects of the single A1408G mutation, which Wang et al. (2012) used, on Neo and Tob inhibition (Table 1; Fig. 2C,F). In both cases, the degree of resistance conferred by A1408G was similar to that conferred by the dual A1408G/G1491U mutation. These strong effects of A1408G and A1408G/G1491U indicate that AG interaction with h44 is critical for the inhibition of translocation.

Removal of $\mathrm{H} 69$ had a smaller impact on AG inhibition of translocation. Mutation $\triangle \mathrm{H} 69$ increased $\mathrm{IC}_{50}$ for $\mathrm{Neo}$,
Par, Gen, and Tob by about 15-, four-, four-, and sixfold, respectively (Table 1; Fig. $2 \mathrm{C}-\mathrm{F}$ ). We also compared the behavior of ribosomes with both h44 and $\mathrm{H} 69$ sites abrogated. This triple A1408G/G1491U/DH69 mutation conferred the highest resistance to Neo and Par (Table 1; Fig. 2C,D). Removal of H69 from A1408G/G1491U ribosomes increased the $\mathrm{IC}_{50}$ for $\mathrm{NeO}$ and Par by sixfold and threefold, respectively, effects similar to those of $\Delta \mathrm{H} 69$ in ribosomes with the h44 site intact. The simplest interpretation of these data is that, for 4,5-substituted 2-DOS compounds, AG-H69 interaction contributes to inhibition through a mechanism that is largely independent of h44. In the case of the 4,6-substituted 2-DOS compound Tob, the triple mutant ribosomes were essentially no more resistant than the A1408G/G1491U ribosomes (Table 1; Fig. 2F). This differs from $\mathrm{Neo}$ and Par cases and suggests that the observed effect of $\Delta \mathrm{H} 69$ on inhibition depends on Tob-h44 interaction. For Gen, the dual h44 mutation A1408G/G1491U conferred complete resistance $\left(I_{50}>2000 \mu \mathrm{M}\right)$, in the presence or absence of H69 (Table 1; Fig. 2E).

We also analyzed inhibition of translocation by $\mathrm{NeO}$ in control and mutant ribosomes in polymix buffer (Ehrenberg et al. 1990), conditions analogous to those of Wang et al. (2012). The results obtained (Fig. 3) were qualitatively similar to those described above (Table 1; Fig. 2C), providing further evidence that Neo-h44 interaction is primarily responsible for the inhibition of translocation.
A

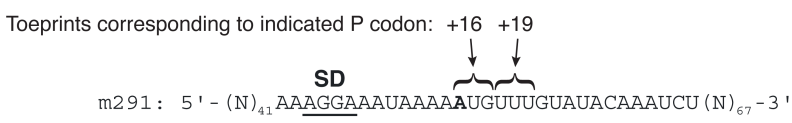

B

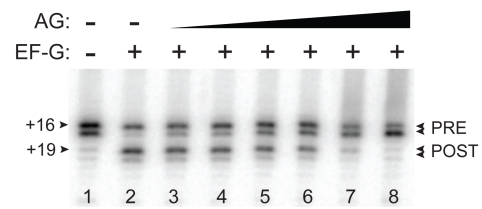

$\mathbf{F}$
C

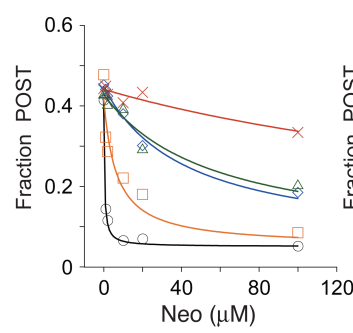

D

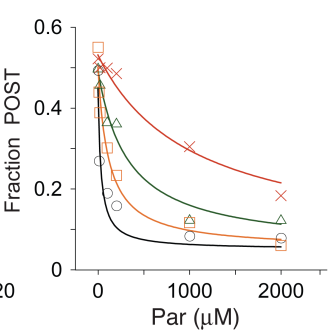

E

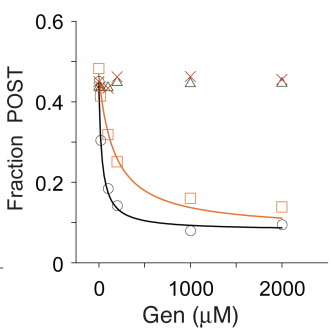

$\mathbf{F}$

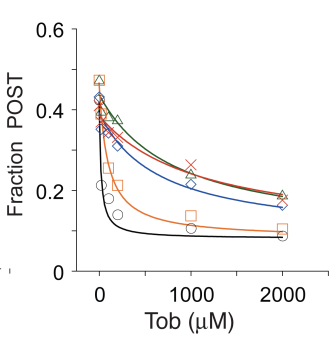

KEY: $\odot$ Control $\neg$ A1408G $\triangle \mathrm{A} 1408 \mathrm{G} / \mathrm{G} 1491 \mathrm{U} \square \triangle \mathrm{H} 69 \quad \leftarrow \mathrm{A} 1408 \mathrm{G} / \mathrm{G} 1491 \mathrm{U} / \Delta \mathrm{H} 69$

FIGURE 2. Inhibition of EF-G-dependent translocation by aminoglycosides. (A) Sequence of model mRNA, m291, with the relevant codons indicated. The first nucleotide of codon 1 (defined as position +1 ) is shown in bold text and the Shine-Dalgarno (SD) sequence is underscored. (B) Example of a toeprinting experiment that measures AG inhibition of translocation. The pretranslocation complex (PRE) was formed by incubating $m 291$-programmed ribosomes with tRNA $^{\text {fMet }}$ to bind the $P$ site and $N$-acetyl-Phe-tRNA ${ }^{\text {Phe }}$ to bind the A site. The complex was further incubated in the absence (lanes 1,2) or presence of AG (lanes 3-8, various concentrations), and then EF-G and GTP were added to promote translocation (lanes 2-8). The position of mRNA was then mapped in each case to quantify the fraction of ribosomes in the post-translocation (POST) state. $(C, D)$ Shown is the extent of translocation (Fraction POST) in control and mutant ribosomes (as indicated, see KEY) plotted against the concentration of $\mathrm{Neo}(C)$, $\operatorname{Par}(D)$, Gen $(E)$, and Tob $(F)$. Data were fit to a modified dose response equation to obtain $I C_{50}$ values (Table 1$)$. 
TABLE 1. AG inhibition of EF-G-dependent translocation in control and mutant ribosomes

\begin{tabular}{lccccc}
\hline AG & Control & A1408G & $\begin{array}{c}\text { A1408G/ } \\
\text { G1491U }\end{array}$ & $\Delta$ H69 & $\begin{array}{c}\text { A1408G/ } \\
\text { G1491U/ } \\
\Delta H 69\end{array}$ \\
\hline Neo & $0.41 \pm 0.03$ & $39 \pm 5$ & $42 \pm 6$ & $6.2 \pm 0.5$ & $270 \pm 30$ \\
Par & $32 \pm 3$ & ND & $330 \pm 30$ & $120 \pm 8$ & $1040 \pm 110$ \\
Tob & $26 \pm 3$ & $620 \pm 70$ & $880 \pm 90$ & $100 \pm 10$ & $1250 \pm 130$ \\
Gen & $36 \pm 4$ & ND & $>2000$ & $220 \pm 30$ & $>2000$ \\
\hline
\end{tabular}

Values represent $I C_{50}(\mu M) \pm S E M$ from three or more independent experiments like those shown in Figure 2. ND, not determined.

\section{The ability of Neo to promote spontaneous reverse translocation is eliminated by h44 mutations}

It has been shown previously that Neo, Par, and Gen can similarly increase the rate of spontaneous reverse translocation (Shoji et al. 2006; Borovinskaya et al. 2008). While the basis of this activity remains unclear, it has been proposed that these AGs shift the microscopic equilibrium of tRNA binding in the transition-state complex (also known as "unlocked" state), thereby enhancing the reaction rate (Shoji et al. 2009b). To determine whether this AG activity involves $\mathrm{h} 44$, we measured spontaneous reverse translocation in control and mutant ribosomes (Fig. 4), as detailed previously (Shoji et al. 2006; Borovinskaya et al. 2008). Esite tRNA ${ }^{\text {fMet }}$ was added to $\mathrm{m} 292$-programmed ribosomes containing $N$-acetyl-Val-tRNA ${ }^{\mathrm{Val}}$ in the P site and the fraction of ribosomes in the POST state was monitored as a function of time. In line with previous observations (Shoji et al. 2006; Borovinskaya et al. 2008), Neo increased $k_{\text {obs }}$ by approximately threefold in control ribosomes. In ribosomes harboring either $\mathrm{A} 1408 \mathrm{G}$ or $\mathrm{G} 1491 \mathrm{U}$, the rate was virtually unaffected by $\mathrm{Neo}$ (Fig. 4). These data clearly indicate that $\mathrm{h} 44$ binding is critical for the ability of Neo to speed reverse translocation. Although there was no EF-G in these reactions, the spontaneous reaction is fundamentally related to EF-G-dependent translocation (Fredrick and Noller 2003; Shoji et al. 2006, 2009b; Fischer et al. 2010; Liu and Fredrick 2013). Hence, these results further implicate AG-h44 interaction in the mechanism of translocation inhibition.

\section{Inhibition of ribosome recycling by aminoglycosides}

Kaji and coworkers showed that RRF/EF-G-dependent ribosome recycling could be strongly inhibited by AGs (Hirokawa et al. 2002), but the basis of this activity has remained unclear. Structural studies have shown that RRF binds the large subunit and causes H69 to swing away from the subunit interface, breaking bridge $\mathrm{B} 2 \mathrm{a} / \mathrm{d}$ (Borovinskaya et al. 2007a). The additional presence of Gen or Par completely suppressed this RRF-induced movement of
H69. It was proposed that $A G$ binding to $H 69$ restricts the dynamics of the helix and stabilizes B2a/d, thereby inhibiting the subunit-splitting step of recycling (Borovinskaya et al. 2007a). Yet, single mutations in h44 confer high-level AG resistance (Recht and Puglisi 2001; Hobbie et al. 2005, 2006a,b; Nessar et al. 2011). The corresponding nucleotides (A1408, G1491, U1495, C1409, and U1406) lie close to the intersubunit bridge $\mathrm{B} 2 \mathrm{a} / \mathrm{d}$, raising the alternative possibility that AG-h44 interaction is involved in recycling inhibition.

To test the role of the $\mathrm{h} 44$ site in recycling inhibition, we used a filter-binding method to assay recycling at various concentrations of AGs. Model post-termination complexes containing radiolabeled tRNA ${ }^{\text {Phe }}$ in the $P$ site were formed, and the tRNA dissociation rate $\left(k_{\text {off }}\right)$ was measured in the absence and presence of RRF, EF-G (GTP), and IF3. The factors stimulated the rate of tRNA release by an order of magnitude, an effect that required all three factors (Fig. 5A). Although quite slow, the observed rate of this reaction is comparable to rates seen previously for analogous POST complexes in which SD-ASD pairing occurs (Peske et al. 2005; Chen et al. 2017). As expected, Neo and Tob inhibited recycling of the control ribosome, with $\mathrm{IC}_{50}$ values of $1.9 \pm 0.3 \mu \mathrm{M}$ and $23 \pm 3 \mu \mathrm{M}$, respectively (Fig. 5B,D,E). Ablation of the h44 site (via mutation A1408G or dual mutation A1408G/G1491U) had virtually no effect on recycling inhibition (Fig. 5C-E). If anything, complexes formed with the mutant ribosomes exhibited slightly smaller $\mathrm{IC}_{50}$ values (Neo IC $C_{50}=1.5 \pm 0.2,1.3 \pm 0.2 \mu \mathrm{M} ;$ Tob IC $50=20 \pm$ $2,18 \pm 2 \mu \mathrm{M})$. These data indicate that AG-h44 interaction plays no role in the inhibition of recycling, as measured in this in vitro assay. The effect of $\Delta \mathrm{H} 69$ could not be investigated because the mutation causes recycling to become independent of RRF (Ali et al. 2006), an observation that we confirmed.

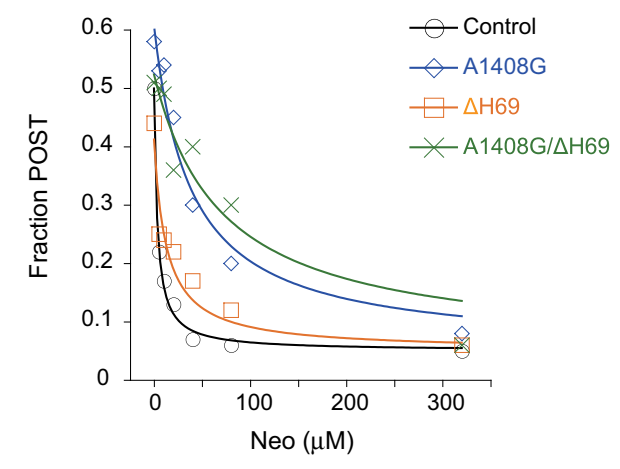

FIGURE 3. Inhibition of EF-G-dependent translocation by Neo in polymix buffer. Shown is the extent of translocation (Fraction POST) in control and mutant ribosomes (as indicated) plotted against the concentration of Neo. Data were fit to a modified dose response equation, yielding the following micromolar $I C_{50}$ values (mean $\pm S E M, n \geq$ 3): Control, $3 \pm 0.4 ; A 1408 G, 45 \pm 10 ; \Delta H 69,15 \pm 3 ; A 1408 G / \Delta H 69$, $130 \pm 30$. 
A

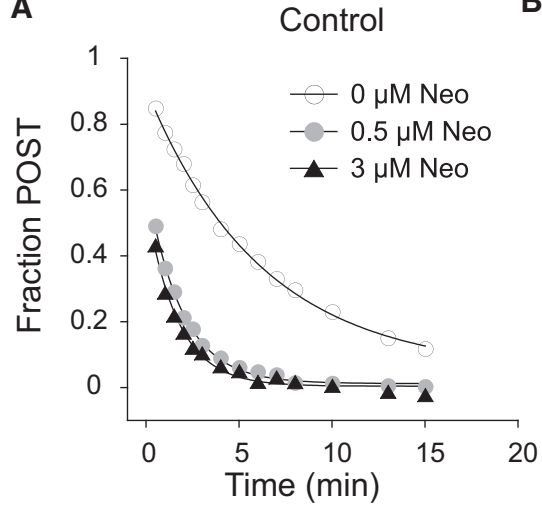

B

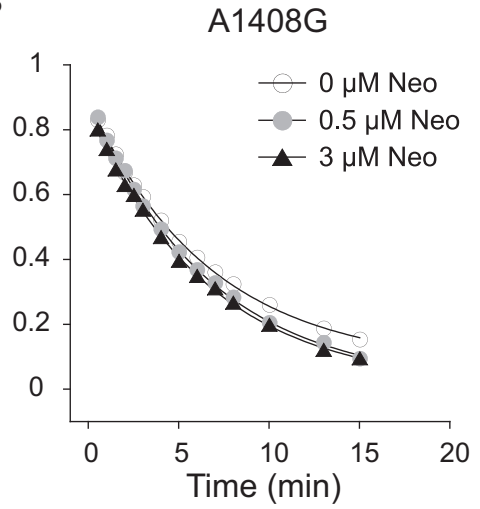

C

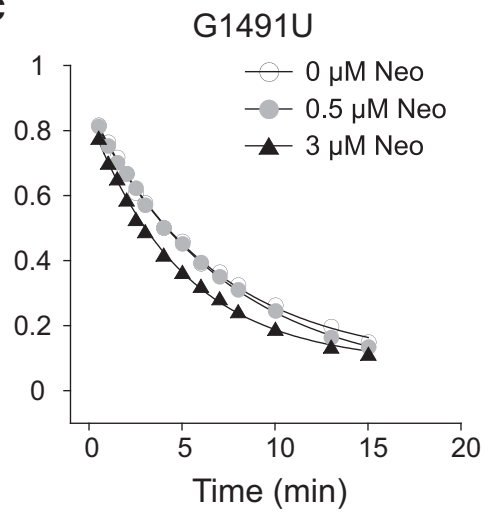

FIGURE 4. The ability of neomycin to stimulate spontaneous reverse translocation depends on the h44 site. Reverse translocation in control (A), A1408G (B), or G1491U (C) ribosomes was measured in the absence and presence of $\mathrm{Neo}$ (as indicated). The fraction of ribosomes in the POST state was plotted versus time, and the data were fit to a single exponential function to obtain the observed rate at $0,0.5$, and $3 \mu \mathrm{M} \mathrm{Neo}$ (respectively): Control, $k_{\mathrm{obs}}=0.16,0.54,0.60 \mathrm{~min}^{-1} ; \mathrm{A} 1408 \mathrm{G}, \mathrm{k}_{\mathrm{obs}}=0.15,0.15,0.15 \mathrm{~min}^{-1} ; \mathrm{G} 1491 \mathrm{U}, \mathrm{k}_{\mathrm{obs}}=0.15,0.14,0.20 \mathrm{~min}^{-1}$.

\section{DISCUSSION}

Our findings help clarify the roles of two AG binding sites in the inhibition of protein synthesis. We demonstrate that $A G$ interaction with the h44 site is primarily responsible for inhibition of translocation. This is consistent with the fact that single mutations in the h44 are sufficient to confer high-level resistance to AGs in vivo (Recht and Puglisi 2001; Hobbie et al. 2005, 2006a,b; Nessar et al. 2011) and challenges an earlier conclusion of Blanchard and coworkers (Wang et al. 2012). Monitoring a fluorescence change in single-molecule studies (Munro et al. 2010), they reported no difference in AG-inhibition between control and A1408G ribosomes and proposed that AG-H69 interaction was key to translocation inhibition (Wang et al. 2012). Translocation is a complex process involving multiple conformational changes of the ribosome, tRNAs, and EF-G. Our suspicion is that their readout-an EF-G-dependent increase in Cy3-tRNA fluorescence intensity-corresponds to another event, related to translocation but distinct from codon-anticodon movement. Indeed, more recent work from the Blanchard laboratory, in which the motions of translocation were followed from multiple perspectives, suggests that codon-anticodon movement with respect to the $30 \mathrm{~S}$ subunit occurs at a later stage in the process (Wasserman et al. 2016).

The ability of AGs to inhibit translocation is reduced to some degree by removal of $\mathrm{H} 69$. The simplest interpretation of these data is that AG-H69 interaction does contribute, albeit modestly, to translocation inhibition. Deletion $\Delta \mathrm{H} 69$ similarly increases the $\mathrm{IC}_{50}$ for $\mathrm{Neo}$ and $\mathrm{Par}$, regardless of whether the primary $\mathrm{h} 44$ site is mutated. Such cumulative effects of $\Delta \mathrm{H} 69$ and $\mathrm{A} 1408 \mathrm{G} / \mathrm{G} 1491 \mathrm{U}$ suggest that for example Par-H69 and Par-h44 interactions act in largely independent ways, each contributing to translocation inhibition. In contrast, $\Delta \mathrm{H} 69$ fails to increase the $\mathrm{IC}_{50}$ for Tob when the primary $\mathrm{h} 44$ site is ablated. This indicates a difference in activity between the 4,6-linked AG Tob and the 4,5linked AGs $\mathrm{NeO}$ and Par, regarding H69. Interestingly, it has been shown that Neo alters the dynamics of the ribosome, stabilizing a semi-rotated conformation (Wang et al. 2012). This activity, attributed to $\mathrm{H} 69$ binding, appears to be specific to the 4,5-linked AGs. Based on these collective observations, we propose that binding of 4,5linked AGs to $\mathrm{H} 69$ stabilizes an intermediate of the process (Wang et al. 2012; Wasserman et al. 2016), which contributes to inhibition.

Another possibility is that the effects of $\Delta \mathrm{H} 69$ are indirect, and AG-H69 interaction plays no role in translocation inhibition. Deletion $\Delta \mathrm{H} 69$ removes the secondary AG binding site, of course, but also disrupts bridge B2a/d, which could weaken AG-h44 interaction and/or its inhibitory effects. Although we introduced two AG resistance mutations in an effort to eliminate the $h 44$ site, low-affinity AG binding to h44 may still occur in A1408G/G1491U ribosomes. If so, $\Delta \mathrm{H} 69$ could indirectly weaken $A G-h 44$ interaction in both control and A1408G/G1491U ribosomes, thereby increasing the $\mathrm{IC}_{50}$ in multiple contexts as observed. Additional experiments will be needed to distinguish whether AG-H69 interaction plays a minor role or no role in the inhibition of translocation.

Based on structural studies, it has been proposed that AG binding to $\mathrm{H} 69$ is responsible for the inhibition of recycling (Borovinskaya et al. 2007a). Our data are consistent with this model, as recycling inhibition appears to be completely independent of $h 44$. Yet, as mentioned above, single nucleotide substitutions in $\mathrm{h} 44$ are sufficient to confer high-level AG resistance in vivo. This implies that AG inhibition of recycling either (i) occurs with little physiological consequence or (ii) is countered somehow in the cell. The latter scenario seems more likely, given that RRF is essential for cell viability (Janosi et al. 1994, 1998; Baba et al. 2006). 
A

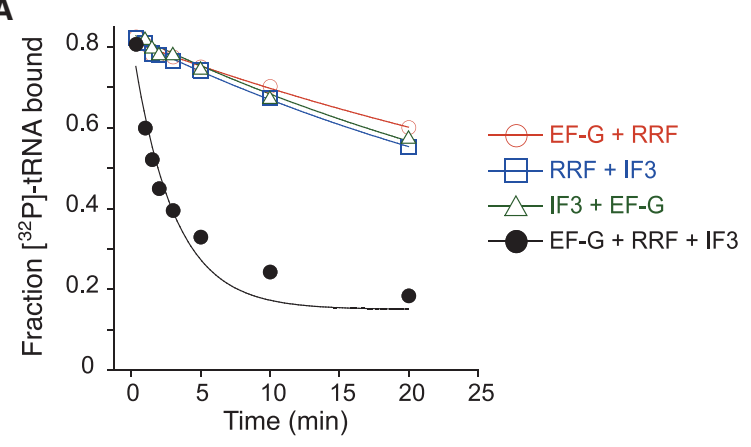

B
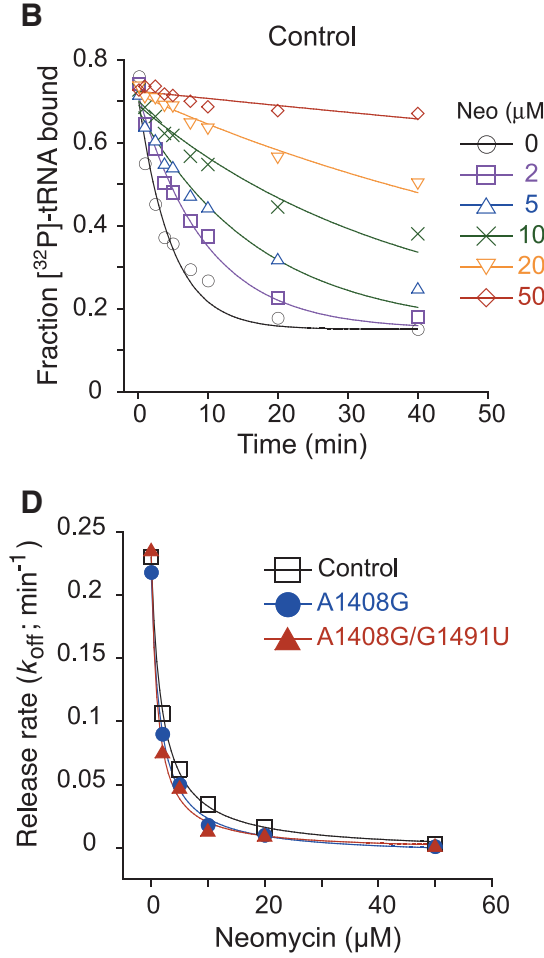

C

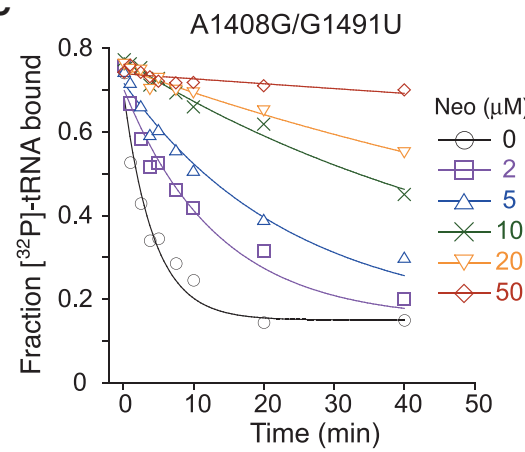

E

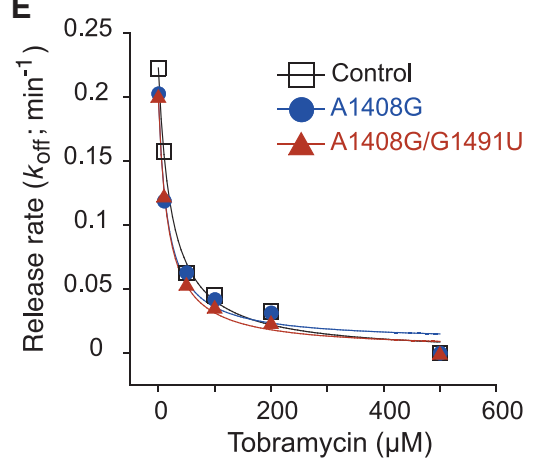

FIGURE 5. Inhibition of ribosome recycling by AGs. (A) An in vitro assay for ribosome recycling. Dissociation of deacyl $3^{\prime}-\left[{ }^{32} \mathrm{P}\right]-\mathrm{tRNA}{ }^{\text {Phe }}$ from the P site of m291-programmed ribosomes was measured in the absence or presence of various factors (as indicated). Stimulation of tRNA release required RRF, EF-G (GTP), and IF3, as reactions with single omissions showed no apparent catalysis. $(B, C)$ Examples of experiments measuring the effect of $\mathrm{Neo}$ (various concentrations, as indicated) on tRNA release from control (B) or A1408G/G1491U (C) ribosomes in the presence of RRF, EF-G (GTP), and IF3. Fraction of radiolabeled tRNA bound was plotted against time, and the data were fit to a single exponential equation to obtain $k_{\text {off. }}(D, E) k_{\text {off }}$ values were plotted as a function of concentration of $\mathrm{Neo}(D)$ and $\mathrm{Tob}(E)$. Data were fit to a modified dose response equation to generate $I_{50}$ values for control, A1408G, and A1408G/ G1491U cases, respectively, as follows: Neo $I_{50}=1.9 \pm 0.3,1.5 \pm 0.2,1.3 \pm 0.2 \mu \mathrm{M}$; Tob $I_{50}=23 \pm 3,20 \pm 2,18 \pm 2 \mu \mathrm{M}$.

\section{MATERIALS AND METHODS}

\section{Subunit purification and reassociation}

Mutations A1408G and G1491T were introduced into plasmid p278MS2 (Youngman and Green 2005), using the QuikChange (Stratagene) method. Plasmid p278MS2 and its derivatives (carrying nonlethal mutations) were moved into $E$. coli $\Delta 7$ prrn strain SQZ10, replacing the resident plasmid. From these strains, $30 \mathrm{~S}$ subunits (control or mutant) were purified, using conventional sucrose-gradient sedimentation as previously described (Qin et al. 2007). Mutation $\Delta \mathrm{H} 69$ has been described previously (Ali et al. 2006), and aptamer-tagged $50 \mathrm{~S}$ subunits (control and mutant) were purified using affinity chromatography as previously described (Youngman and Green 2005; Liu and Fredrick 2013, 2015).

Reassociated 70S ribosomes were formed from purified subunits (Shoji et al. 2009a; Liu and Fredrick 2013). 30 S subunits (control or mutant) were heat activated in the presence of $20 \mathrm{mM} \mathrm{Mg}^{2+}$ at $42^{\circ} \mathrm{C}$ for $20 \mathrm{~min}$ and then mixed with an equal amount of $50 \mathrm{~S}$ subunits (control or mutant) and further incubated at $37^{\circ} \mathrm{C}$ for $20 \mathrm{~min}$.

\section{Factors, tRNAs, and other reagents}

EF-G-His6, IF3-His6, and RRF were purified as previously described (MacDougall et al. 1997; Dallas and Noller 2001; Fredrick and Noller 2002). Purified tRNA ${ }^{\text {fMet }}$, tRNA ${ }^{\text {Phe }}$, and tRNA ${ }^{\mathrm{Val}}$ were purchased from Chemical Block, charged, and acetylated as previously described (Walker and Fredrick 2008). Messenger RNA was made by in vitro transcription and gel purified (Fredrick and Noller 2002). AGs were purchased from Sigma-Aldrich or Fisher Scientific.

\section{Translocation assays}

EF-G-dependent translocation was measured by toeprinting (Shoji et al. 2006; Fosso et al. 2015). Briefly, pretranslocation (PRE) complexes $(0.5 \mu \mathrm{M}$; final concentrations indicated throughout) containing deacylated tRNA ${ }^{\text {fMet }}$ in the $P$ site and $N$ acetyl-Phe-tRNA ${ }^{\text {Phe }}$ in the $A$ site were formed at $37^{\circ} \mathrm{C}$ in buffer A $(10 \mathrm{mM}$ Tris$\mathrm{HCl} \mathrm{pH} 8.0,10 \mathrm{mM} \mathrm{MgCl} 2,65 \mathrm{mM}$ $\mathrm{NH}_{4} \mathrm{Cl}, 1 \mathrm{mM}$ DTT). AG (variable concentration) was added, followed 10 min later by EF-G $(1 \mu \mathrm{M})$ and GTP $(0.3 \mathrm{mM})$. Under single-turnover conditions like these, the rate of translocation is too fast to measure manually (Pan et al. 2007; Walker et al. 2008; Liu and Fredrick 2013; Holtkamp et al. 2014). After 5 min, an end point chosen merely for practical reasons, complexes were subjected to primer extension analysis. Toeprints were quantified and the extent of translocation determined, as described previously (Shoji et al. 2006). The fraction of ribosomes in the POST state $(F)$ were plotted against the AG concentration $(A)$, using KaleidaGraph (Synergy Software), and the data were fit to the modified dose 
response equation

$$
F=F_{0}+F_{\max } /\left[1+(A / B)^{C}\right]
$$

where $F_{0}$ represents $F$ prior to EF-G and GTP addition (set to 0.05 based on control experiments), $F_{\text {max }}$ represents the maximal $F$ value, $B$ represents $I C_{50}$, and $C$ represents the Hill coefficient. Initial data fitting showed that the Hill coefficient fell between 0.8 and 1.2 , and hence $C$ was set to 1.0 to ensure uniform comparisons.

Spontaneous reverse translocation was measured as detailed previously (Shoji et al. 2006; Borovinskaya et al. 2007b, 2008; Liu and Fredrick 2013). Briefly, m292-programmed ribosomes $(0.5 \mu \mathrm{M})$ containing $\mathrm{N}$-acetyl-Val-tRNA ${ }^{\mathrm{Val}}$ in the $\mathrm{P}$ site were incubated in polymix buffer $(5 \mathrm{mM}$ potassium phosphate $\mathrm{pH} 7.3,95$ $\mathrm{mM} \mathrm{KCl}, 5 \mathrm{mM} \mathrm{NH}_{4} \mathrm{Cl}, 0.5 \mathrm{mM} \mathrm{CaCl}_{2}, 5 \mathrm{mM}$ magnesium acetate, $8 \mathrm{mM}$ putrescine, $1 \mathrm{mM}$ spermidine, $1 \mathrm{mM} \mathrm{DTT}$ ) with various concentrations of $\mathrm{Neo}$ at $37^{\circ} \mathrm{C}$ for $10 \mathrm{~min}$. Reverse translocation was initiated by adding deacylated tRNA ${ }^{f M e t}(8 \mu \mathrm{M})$ at time $t=0$. Aliquots were removed at various time points and subjected to primer extension analysis. Fraction POST was quantified and plotted as a function of time. Data were fit to a single exponential function to obtain the observed rate and amplitude of the reaction.

\section{Ribosome recycling assay}

Ribosome recycling was measured using a double-membrane filtration method (Fahlman and Uhlenbeck 2004). Typically, $20 \mathrm{nM}$ $\left[3^{\prime}-{ }^{32} \mathrm{P}\right]-$ tRNA ${ }^{\text {Phe }}, \mathrm{m} 291(1.5 \mu \mathrm{M})$ and ribosomes $(1 \mu \mathrm{M})$ were incubated at $37^{\circ} \mathrm{C}$ in buffer $A$ for 20 min to bind the $P$ site. At $t=0$, a portion of the reaction $(2 \mu \mathrm{L})$ was diluted 100 -fold in buffer containing excess unlabeled tRNA ${ }^{\text {Phe }}(0.2 \mu \mathrm{M})$ and GTP $(0.3 \mathrm{mM})$, with or without EF-G $(0.3 \mu \mathrm{M})$, RRF $(0.3 \mu \mathrm{M})$, IF3 $(0.3 \mu \mathrm{M})$, and $A G$ (variable concentration) as specified. Aliquots $(20 \mu \mathrm{L})$ were then filtered through a bilayer of nitrocellulose (NitroBind, GE Healthcare) and positively charged nylon (Hybond- $\mathrm{N}^{+}$) membranes (GE Healthcare) at various time points. Ribosome-bound and free tRNA were captured by the top and bottom membranes, respectively (Fahlman and Uhlenbeck 2004; Shoji et al. 2009a). Membranes were immediately washed with $150 \mu \mathrm{L}$ of buffer, dried, and exposed to a phosphor screen (GE Healthcare). The fraction of tRNA bound was quantified and plotted against time. Dissociation rate $\left(k_{\text {off }}\right)$ was determined by fitting the data to a single exponential function. Then, $k_{\text {off }}$ was plotted as a function of $A G$ concentration, and data were fit to a dose response equation analogous to the one described above, yielding the $\mathrm{IC}_{50}$ value.

\section{ACKNOWLEDGMENTS}

This work was supported by National Institutes of Health (grant no. GM072528).

Received August 20, 2018; accepted November 6, 2018.

\section{REFERENCES}

Ali IK, Lancaster L, Feinberg J, Joseph S, Noller HF. 2006. Deletion of a conserved, central ribosomal intersubunit RNA bridge. Mol Cell 23: 865-874. doi:10.1016/j.molcel.2006.08.011

Baba T, Ara T, Hasegawa M, Takai Y, Okumura Y, Baba M, Datsenko KA, Tomita M, Wanner BL, Mori H. 2006. Construction of Escherichia coli K-12 in-frame, single-gene knockout mutants: the Keio collection. Mol Syst Biol 2: 2006.0008. doi:10.1038/ msb4100050

Balakrishnan R, Oman K, Shoji S, Bundschuh R, Fredrick K. 2014. The conserved GTPase LepA contributes mainly to translation initiation in Escherichia coli. Nucleic Acids Res 42: 13370-13383. doi: 10.1093/nar/gku1098

Borovinskaya MA, Pai RD, Zhang W, Schuwirth BS, Holton JM, Hirokawa G, Kaji H, Kaji A, Cate JH. 2007a. Structural basis for aminoglycoside inhibition of bacterial ribosome recycling. Nat Struct Mol Biol 14: 727-732. doi:10.1038/nsmb1271

Borovinskaya MA, Shoji S, Holton JM, Fredrick K, Cate JHD. 2007b. A steric block in translation caused by the antibiotic spectinomycin. ACS Chem Biol 2: 545-552. doi:10.1021/cb700100n

Borovinskaya MA, Shoji S, Fredrick K, Cate JH. 2008. Structural basis for hygromycin B inhibition of protein biosynthesis. RNA 14: 15901599. doi:10.1261/rna.1076908

Cabañas MJ, Vázquez D, Modolell J. 1978. Inhibition of ribosomal translocation by aminoglycoside antibiotics. Biochem Biophys Res Commun 83: 991-997. doi:10.1016/0006-291X(78)91493-6

Carter AP, Clemons WM, Brodersen DE, Morgan-Warren RJ, Wimberly BT, Ramakrishnan V. 2000. Functional insights from the structure of the $30 \mathrm{~S}$ ribosomal subunit and its interactions with antibiotics. Nature 407: 340-348. doi:10.1038/35030019

Chen Y, Kaji A, Kaji H, Cooperman BS. 2017. The kinetic mechanism of bacterial ribosome recycling. Nucleic Acids Res 45: 10168-10177. doi:10.1093/nar/gkx694

Dallas A, Noller HF. 2001. Interaction of translation initiation factor 3 with the $30 \mathrm{~S}$ ribosomal subunit. Mol Cell 8: 855-864. doi: 10.1016/S1097-2765(01)00356-2

Davies J, Gorini L, Davis BD. 1965. Misreading of RNA codewords induced by aminoglycoside antibiotics. Mol Pharmacol 1: 93-106.

Davies J, Jones DS, Khorana HG. 1966. A further study of misreading of codons induced by streptomycin and neomycin using ribopolynucleotides containing two nucleotides in alternating sequence as templates. J Mol Biol 18: 48-57. doi:10.1016/S0022-2836(66) 80075-X

Devaraj A, Shoji S, Holbrook ED, Fredrick K. 2009. A role for the 30S subunit $E$ site in maintenance of the translational reading frame. RNA 15: 255-265. doi:10.1261/rna.1320109

Ehrenberg M, Bilgin N, Kurland CG. 1990. Design and use of a fast and accurate in vitro translation system. In Ribosomes and protein synthesis-a practical approach (ed. Spedding G), pp. 101-129. IRL Press, Oxford, UK.

Fahlman RP, Uhlenbeck OC. 2004. Contribution of the esterified amino acid to the binding of aminoacylated tRNAs to the ribosomal $\mathrm{P}$ - and A-sites. Biochemistry 43: 7575-7583. doi:10.1021/bi0495836

Fischer N, Konevega AL, Wintermeyer W, Rodnina MV, Stark H. 2010. Ribosome dynamics and tRNA movement by time-resolved electron cryomicroscopy. Nature 466: 329-333. doi:10.1038/ nature09206

Fosso MY, Zhu H, Green KD, Garneau-Tsodikova S, Fredrick K. 2015. Tobramycin variants with enhanced ribosome-targeting activity. Chembiochem 16: 1565-1570. doi:10.1002/cbic.201500256

Fredrick K, Noller HF. 2002. Accurate translocation of mRNA by the ribosome requires a peptidyl group or its analog on the tRNA moving into the 30S P site. Mol Cell 9: 1125-1131. doi:10.1016/S10972765(02)00523-3

Fredrick K, Noller HF. 2003. Catalysis of ribosomal translocation by sparsomycin. Science 300: 1159-1162. doi:10.1126/science.1084571

Hartz D, McPheeters DS, Gold L. 1989. Selection of the initiator tRNA by Escherichia coli initiation factors. Genes Dev 3: 1899-1912. doi:10.1101/gad.3.12a.1899

Hirokawa G, Kiel MC, Muto A, Selmer M, Raj VS, Liljas A, Igarashi K, Kaji H, Kaji A. 2002. Post-termination complex disassembly by 
ribosome recycling factor, a functional tRNA mimic. EMBO J 21: 2272-2281. doi:10.1093/emboj/21.9.2272

Hobbie SN, Pfister P, Brüll C, Westhof E, Böttger EC. 2005. Analysis of the contribution of individual substituents in 4,6-aminoglycosideribosome interaction. Antimicrob Agents Chemother 49: 51125118. doi:10.1128/AAC.49.12.5112-5118.2005

Hobbie SN, Bruell C, Kalapala S, Akshay S, Schmidt S, Pfister P, Böttger EC. 2006a. A genetic model to investigate drug-target interactions at the ribosomal decoding site. Biochimie 88: 1033 1043. doi:10.1016/j.biochi.2006.04.008

Hobbie SN, Pfister P, Bruell C, Sander P, Francois B, Westhof E, Böttger EC. 2006b. Binding of neomycin-class aminoglycoside antibiotics to mutant ribosomes with alterations in the $A$ site of 16S rRNA. Antimicrob Agents Chemother 50: 1489-1496. doi: 10.1128/AAC.50.4.1489-1496.2006

Holtkamp W, Cunha CE, Peske F, Konevega AL, Wintermeyer W, Rodnina MV. 2014. GTP hydrolysis by EF-G synchronizes tRNA movement on small and large ribosomal subunits. EMBO J 33: 1073-1085. doi:10.1002/embj.201387465

Janosi L, Shimizu I, Kaji A. 1994. Ribosome recycling factor (ribosome releasing factor) is essential for bacterial growth. Proc Natl Acad Sci 91: 4249-4253. doi:10.1073/pnas.91.10.4249

Janosi L, Mottagui-Tabar S, Isaksson LA, Sekine Y, Ohtsubo E, Zhang S, Goon S, Nelken S, Shuda M, Kaji A. 1998. Evidence for in vivo ribosome recycling, the fourth step in protein biosynthesis. EMBO J 17: 1141-1151. doi:10.1093/emboj/17.4.1141

Liu Q, Fredrick K. 2013. Contribution of intersubunit bridges to the energy barrier of ribosomal translocation. Nucleic Acids Res 41: 565 574. doi:10.1093/nar/gks1074

Liu Q, Fredrick K. 2015. Roles of helix H69 of 23S rRNA in translation initiation. Proc Natl Acad Sci 112: 11559-11564. doi:10.1073/ pnas. 1507703112

Liu Q, Fredrick K. 2016. Intersubunit bridges of the bacterial ribosome. J Mol Biol 428: 2146-2164. doi:10.1016/j.jmb.2016.02.009

MacDougall J, Holst-Hansen P, Mortensen KK, Freistroffer DV, Pavlov MY, Ehrenberg M, Buckingham RH. 1997. Purification of active Escherichia coli ribosome recycling factor (RRF) from an osmo-regulated expression system. Biochimie 79: 243-246. doi: 10.1016/S0300-9084(97)83511-0

Magnet S, Blanchard JS. 2005. Molecular insights into aminoglycoside action and resistance. Chem Rev 105: 477-498. doi: 10.1021/cr0301088

McGarry KG, Walker SE, Wang H, Fredrick K. 2005. Destabilization of the $P$ site codon-anticodon helix results from movement of tRNA into the P/E hybrid state within the ribosome. Mol Cell 20: 613622. doi:10.1016/j.molcel.2005.10.007

Misumi M, Nishimura T, Komai T, Tanaka N. 1978. Interaction of kanamycin and related antibiotics with the large subunit of ribosomes and the inhibition of translocation. Biochem Biophys Res Commun 84: 358-365. doi:10.1016/0006-291X(78)90178-X

Munro JB, Wasserman MR, Altman RB, Wang L, Blanchard SC. 2010. Correlated conformational events in EF-G and the ribosome regulate translocation. Nat Struct Mol Biol 17: 1470-1477. doi: 10.1038/nsmb.1925

Nessar R, Reyrat JM, Murray A, Gicquel B. 2011. Genetic analysis of new $16 \mathrm{~S}$ rRNA mutations conferring aminoglycoside resistance in Mycobacterium abscessus. J Antimicrob Chemother 66: 17191724. doi:10.1093/jac/dkr209

Ogle JM, Brodersen DE, Clemons WM Jr, Tarry MJ, Carter AP, Ramakrishnan V. 2001. Recognition of cognate transfer RNA by the 30 S ribosomal subunit. Science 292: 897-902. doi:10.1126/ science. 1060612

Ogle JM, Murphy FV, Tarry MJ, Ramakrishnan V. 2002. Selection of tRNA by the ribosome requires a transition from an open to a closed form. Cell 111: 721-732. doi:10.1016/S0092-8674(02)01086-3
Ogle JM, Carter AP, Ramakrishnan V. 2003. Insights into the decoding mechanism from recent ribosome structures. Trends Biochem Sci 28: 259-266. doi:10.1016/S0968-0004(03)00066-5

Pan D, Kirillov SV, Cooperman BS. 2007. Kinetically competent intermediates in the translocation step of protein synthesis. Mol Cell 25: 519-529. doi:10.1016/j.molcel.2007.01.014

Perez-Fernandez D, Shcherbakov D, Matt T, Leong NC, Kudyba I, Duscha S, Boukari H, Patak R, Dubbaka SR, Lang K, et al. 2014. 4'-O-substitutions determine selectivity of aminoglycoside antibiotics. Nat Commun 5: 3112. doi:10.1038/ncomms4112

Peske F, Savelsbergh A, Katunin VI, Rodnina MV, Wintermeyer W. 2004. Conformational changes of the small ribosomal subunit during elongation factor G-dependent tRNA-mRNA translocation. J Mol Biol 343: 1183-1194. doi:10.1016/j.jmb.2004.08.097

Peske F, Rodnina MV, Wintermeyer W. 2005. Sequence of steps in ribosome recycling as defined by kinetic analysis. Mol Cell 18: 403412. doi:10.1016/j.molcel.2005.04.009

Qin D, Abdi NM, Fredrick K. 2007. Characterization of 16S rRNA mutations that decrease the fidelity of translation initiation. RNA 13: 2348-2355. doi:10.1261/rna.715307

Recht MI, Puglisi JD. 2001. Aminoglycoside resistance with homogeneous and heterogeneous populations of antibiotic-resistant ribosomes. Antimicrob Agents Chemother 45: 2414-2419. doi: 10.1128/AAC.45.9.2414-2419.2001

Salian S, Matt T, Akbergenov R, Harish S, Meyer M, Duscha S, Shcherbakov D, Bernet BB, Vasella A, Westhof E, et al. 2012. Structure-activity relationships among the kanamycin aminoglycosides: role of ring I hydroxyl and amino groups. Antimicrob Agents Chemother 56: 6104-6108. doi:10.1128/AAC.01326-12

Satpati P, Sund J, Aqvist J. 2014. Structure-based energetics of mRNA decoding on the ribosome. Biochemistry 53: 1714-1722. doi: $10.1021 / \mathrm{bi} 5000355$

Shoji S, Walker SE, Fredrick K. 2006. Reverse translocation of tRNA in the ribosome. Mol Cell 24:931-942. doi:10.1016/j.molcel. 2006.11.025

Shoji S, Abdi NM, Bundschuh R, Fredrick K. 2009a. Contribution of ribosomal residues to P-site tRNA binding. Nucleic Acids Res 37: 4033-4042. doi:10.1093/nar/gkp296

Shoji S, Walker SE, Fredrick K. 2009b. Ribosomal translocation: one step closer to the molecular mechanism. ACS Chem Biol 4: 93107. doi:10.1021/cb8002946

Studer SM, Feinberg JS, Joseph S. 2003. Rapid kinetic analysis of EFG-dependent mRNA translocation in the ribosome. $J$ Mol Biol 327: 369-381. doi:10.1016/S0022-2836(03)00146-3

Walker SE, Fredrick K. 2006. Recognition and positioning of mRNA in the ribosome by tRNAs with expanded anticodons. J Mol Bio/ 360: 599-609. doi:10.1016/j.jmb.2006.05.006

Walker SE, Fredrick K. 2008. Preparation and evaluation of acylated tRNAs. Methods 44: 81-86. doi:10.1016/j.ymeth.2007.09.003

Walker SE, Shoji S, Pan D, Cooperman BS, Fredrick K. 2008. Role of hybrid tRNA-binding states in ribosomal translocation. Proc Natl Acad Sci 105: 9192-9197. doi:10.1073/pnas.0710146105

Wang L, Pulk A, Wasserman MR, Feldman MB, Altman RB, Cate JH, Blanchard SC. 2012. Allosteric control of the ribosome by smallmolecule antibiotics. Nat Struct Mol Biol 19: 957-963. doi: $10.1038 / \mathrm{nsmb} .2360$

Wasserman MR, Alejo JL, Altman RB, Blanchard SC. 2016. Multiperspective smFRET reveals rate-determining late intermediates of ribosomal translocation. Nat Struct Mol Biol 23: 333-341. doi:10.1038/nsmb.3177

Youngman EM, Green R. 2005. Affinity purification of in vivo-assembled ribosomes for in vitro biochemical analysis. Methods 36: 305-312. doi:10.1016/j.ymeth.2005.04.007

Zhang J, Pavlov MY, Ehrenberg M. 2018. Accuracy of genetic code translation and its orthogonal corruption by aminoglycosides and $\mathrm{Mg}^{2+}$ ions. Nucleic Acids Res 46: 1362-1374. doi:10.1093/ nar/gkx1256 

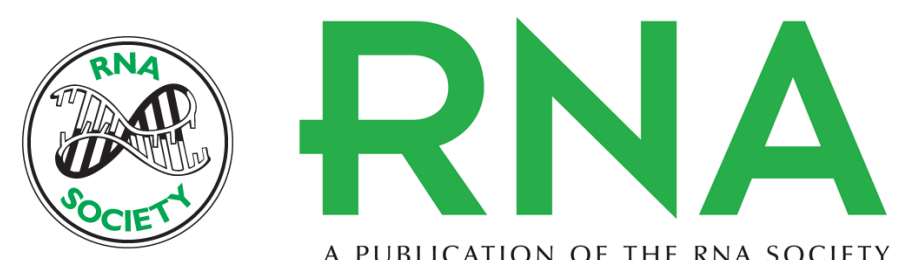

A PUBLICATION OF THE RNA SOCIETY

\section{Roles of specific aminoglycoside-ribosome interactions in the inhibition of translation}

Lanqing Ying, Hongkun Zhu, Shinichiro Shoji, et al.

RNA 2019 25: 247-254 originally published online November 9, 2018

Access the most recent version at doi:10.1261/rna.068460.118

\section{References This article cites 57 articles, 17 of which can be accessed free at: http://rnajournal.cshlp.org/content/25/2/247.full.html\#ref-list-1 \\ Creative This article is distributed exclusively by the RNA Society for the first 12 months after the Commons full-issue publication date (see http://rnajournal.cshlp.org/site/misc/terms.xhtml). After 12 License months, it is available under a Creative Commons License (Attribution-NonCommercial 4.0 International), as described at http://creativecommons.org/licenses/by-nc/4.0/.}

Email Alerting Receive free email alerts when new articles cite this article - sign up in the box at the Service top right corner of the article or click here. 